\title{
Os Fios Condutores do PDE são antigos
}

Resumo:

O texto apresenta uma análise crítica do Plano de Desenvolvimento da Educação - PDE, lançado em abril de 2007 pelo Governo Federal. Discutindo os fios condutores do Plano, - trabalho analisa as propostas de regulação e financiamento da política federal em questão, demonstrando

Palavras-chave: PDE; Politica Educacional. impacto na educação básica brasileira As conclusões apontam para o reconhecimento da desvalorização profissional intrínseca à proposta evidenciando que o PDE se trata apenas de continuidade do ideário político pedagógico implementado nos anos $\mathrm{FHC}$.
No final de abril de 2007 o governo federa lançou um Plano de Desenvolvimento da Educação - PDE, reunindo um conjunto de 27 ações (depois ampliadas para 40). Anunciado como o PAC da Educação, capaz de contribuir em médio prazo para a reversão dos indicadores pouco animadores da educação nacional, o PDE se apresenta como um enorme guardachuva para um conjunto de ações préexistentes no Ministério da Educação algumas ações novas ou remodeladas que merecem uma análise pormenorizada Independente da análise que abaixo busco fazer, o PDE deverá se transformar no programa educacional de governo realmente existente no segundo mandato de Lula e os seus resultados irão determinar - balanço que sobre ele será feito. Esse artigo é um esforço para identificar quais são os fios condutores presentes, nem sempre de forma explícita, no Plano de Desenvolvimento da Educação.

\section{O FIO DA REGULAÇÃO}

O primeiro fio condutor é a concepção de que a principal tarefa do Ministério da Educação é a de impor uma regulação do sistema educacional, essencialmente baseada em instrumentos de avaliação de larga escala, ou seja, exames que mensurem a aprendizagem dos alunos representando uma linha de continuidade com a política educacional hegemônica no nosso país nas últimas décadas.
As avaliações padronizadas de rendimento escolar dos alunos surgiram no bojo das reformas educacionais conservadoras inglesas e americanas nos anos 80 , sendo fundamentais para promoção de quasemercados no setor educacional, combinando regulação do estado e introdução da lógica do mercado no domínio público. Apostam que a melhoria do rendimento dos alunos pode ser alcançada mediante a concorrência entre as escolas, através de publicidade negativa divulgação de resultados comparáveis) que estimulariam mudança de atitude dos gestores. A avaliação de monitoramento permite ampliação das formas de controle do Estado sobre o currículo e as formas de regulação do sistema escolar, como também sobre os recursos aplicados na área.

Diante do peso da oferta do setor público na educação básica, a implantação dessas políticas na América Latina teve minimizado o seu caráter puramente mercadológico e de concorrência entre escolas, prevalecendo sua utilização como forma de identificação das carências e como elemento decisivo na alocação dos recursos públicos. Ou seja, o objetivo passou a ser transformar a avaliação em um instrumento com capacidade de incidir na realidade educacional. Porém essa incidência operaria uma substituição das políticas de corte universalista pelas estratégias particularistas, direcionadas a grupos específicos e que foram se ornando hegemônicas com o predomínio da focalização nas políticas públicas. 
Todo o PDE está ancorado justamente na criação do Índice de Desenvolvimento da Educação Brasileira - IDEB, que pondera os resultados do SAEB, do Prova Brasil e dos indicadores de desempenho captados pelo censo escolar (evasão, aprovação e reprovação). Cria um indicador que varia de zero a dez, desdobrável por estado, por município e por redes de ensino. A partir da construção do IDEB, o MEC vinculará repasse de recursos oriundos do FNDE à assinatura de compromisso dos gestores municipais com determinadas metas de melhoria dos seus indicadores ao longo de determinado período.

Faz parte desse fio condutor a compreensão de que é possível avaliar uma rede de ensino utilizando somente indicadores de avaliação de aprendizagem dos alunos. Essa visão mostrou-se equivocada quando da sua implementação pelo Exame Nacional de Cursos, que pretendeu avaliar a qualidade de uma determinada escola superior através do desempenho de seus alunos, abstraindo - diferenciado grau de dificuldade para ingressar em dada instituição, o que por si só já diferencia o perfil destes alunos e sem considerar o valor agregado que efetivamente tal instituição aporta ao aluno ao final do curso. Sua substituição pela metodologia do ENADE não provocou pelo visto nenhum aprendizado no interior do Ministério.

$\mathrm{O}$ anúncio de mais um exame em grande escala, desta vez direcionado a avaliar as crianças de seis a oito anos de idade confirmador da prevalência dessa concepção Apesar do SAEB emais recentemente oPROVA BRASIL já oferecerem informações suficientes acerca do desempenho de nossos alunos no que diz respeito à aprendizagem, o governo Lula pretende investir recursos públicos em uma outra prova, que no máximo irá comprovar o que os outros exames identificaram.
Aspectos influenciadores no desempenho dos alunos foram esquecidos pelo MEC, dentre os quais destaco a existência de valores diferenciados de investimento por aluno, os quais são frutos da política de fundos estaduais baseados na arrecadação tributária de cada ente federado. Não é razoável esperar que os 1000 municípios com piores indicadores no IDEB consigam cumprir metas de melhoria educacional sem que essa situação seja qualitativamente superada. É bom registrar que estamos nos referindo a municípios localizados majoritariamente nos oito estados (um do Norte e sete do Nordeste) que conviverão com um custo-aluno de $\mathrm{R} \$$ 946,29 anuais, ou dito de outra forma, terão que superar suas enormes debilidades com "expressivos" $\mathrm{R} \$ 78,85$ mensais.

Além do diferenciado custo-aluno vale lembrar que, a exemplo do processo de avaliação do ensino superior, seria possível agregar ao indicador informações disponíveis atualmente no censo escolar sobre as condições de ensino que os alunos dos 1000 municípios com pior desempenho convivem. Certamente essas informações ajudariam a desnudar os enormes desafios a serem superados para alcançar melhores índices de aprendizagem.

Por fim, é importante considerar que a pressão externa tem levado a um super dimensionamento das possibilidades de impacto do uso das informações na melhoria da qualidade do ensino. É importante ponderar sobre os custos enormes envolvidos na produção de um grande número de dados, os quais o próprio governo reconhece sua baixa utilização pelos gestores educacionais. E, além disso, existe questionamento sobre o impacto deste investimento na reversão do quadro desafiante de nossa educação.

\section{O FIO DO FINANCIAMENTO}

Um segundo fio condutor diz respeito ao papel da União no financiamento da educação básica e real possibilidade dos recursos aportados incidirem sobre os indicadores dos alunos das redes estaduais e municipais de ensino. Numa leitura do material até agora disponível não é possível identificar o quanto de dinheiro novo será aportado para a educação básica a partir do PDE. No geral transparece um realinhamento das linhas de financiamento do FNDE, pondo fim à dispersão de recursos via pequenos projetos (os conhecidos PTAs) de apoio aos municípios e estados. Mesmo quando o PDE apresenta inovações alentadoras como a linha de financiamento para construção, reforma e compra de equipamentos para escolas de educação infantil, os valores são irrisórios diante da distância que nos separa do cumprimento das metas do Plano Nacional de Educação. O Prolnfância poderá propiciar a construção de escolas para abrigar em média 48 mil novas crianças por ano, que representa menos que $1 \%$ das vagas registradas pelo censo escolar em 2006 na educação infantil.

Ao condicionar o repasse de recursos do FNDE à assinatura de metas pelos gestores municipais, implicitamente o MEC está afirmando que o montante de recursos disponíveis a serem repassados via parecer de especialistas que irão visitar os municípios será suficiente para impactar em médio prazo os indicadores educacionais. Ou caso contrário, o MEC estará afirmando pela enésima vez que o caos da educação é apenas um problema gerencial, resolvive comasalutar pressão institucional regulatória do poder central sobre os "irresponsáveis" gestores municipais.
Considero que os recursos existentes no FNDE não impactaram positivamente os indicadores educacionais por dois motivos relevantes. O primeiro está relacionado à postura autoritária do poder central, que constrói linhas de financiamento a partir de conclusões acerca das causas do fraco desempenho de nossas redes construídas de forma vertical, sem interação com os entes federados ou debate com o mundo acadêmico que pesquisa sobre 0 assunto Segundo, porque os recursos vinculados à manutenção e desenvolvimento da educação disponíveis nos estados e municípios para 2007 somam um pouco mais de 57 bilhões de reais, sem contabilizar a complementação da União (no caso de 2 bilhões conforme regras da emenda constitucional 53). Acredita que valores que talvez cheguem a 2 bilhões por ano irão impactar significativamente os indicadores não é aceitável.

Por isso concluo que o IDEB é mais um instrumento regulatório do que um definidor de critérios para uma melhor aplicação dos recursos da União visando alterar indicadores educacionais. $\mathrm{O}$ resultado de cada município e de cada estado será (e já está sendo) utilizado para ranquear as redes de ensino, para acirrar a competição e para pressionar, via opinião pública, alcance de melhores resultados. Ou seja a função do MEC assumida pelo governo Lula mantém a lógica perversa vigente durante doze anos de FHC

Um exemplo relevante de como o governo federal não enfrenta o debate da necessária e urgente revisão do seu papel no financiamento da educação básica são duas ações lançadas no PDE: a linha de crédito do BNDES para aquisição de veículos escolares e os critérios estabelecidos para definição de cidadespólo para construção de CEFETs. 
No primeiro caso, o governo lançou o Programa "Caminho da Escola", que consiste numa linha de financiamento via BNDES para municípios e estados adquirirem ônibus e barcos. A previsão é que sejam adquiridos 2.500 veículos em três anos através de pregão nacional. Os entes federados se habilitarão a receber empréstimo do BNDES com juros e condições facilitados. Além dos entes federados, também os empresários do setor de transporte escolar serão atendidos com igual montante de recursos. Apesar de ser uma iniciativa bem vinda, pois permitirá a alguns municípios aumentarem sua frota ou renová-la, a proposta não enfrenta o principal nó do transporte escolar brasileiro que é a sua sustentabilidade financeira. Hoje, depois do pagamento de pessoal a principal despesa municipal é com o custeio direto ou terceirizado do transporte de alunos. O Programa Nacional do Transporte Escolar, financiado com recursos bloqueados do salário-educação antes de sua distribuição entre os entes federados, não cobre 10\% das despesas realizadas. Um aporte maior de recursos do governo federal para diminuir o peso dessa despesa provocaria a migração de importantes recursos do MDE para ações pedagógicas que poderiam elevar o padrão de qualidade educacional.

É animador o anúncio no PDE de que o presidente Lula está disposto a cumprir o compromisso de campanha de instalar uma escola técnica federal em cada cidade-pólo do país. Aplaudo toda iniciativa governamental que significa retomar a participação pública na oferta de ensino profissionalizante, um reclamo da juventude e elemento importante para retirar da estagnação econômica as regiões mais pobres do país. Porém, a construção das novas escolas está condicionada a contrapartidas municipais, algumas obrigatórias e outras complementares. Minha avaliação é de que estaremos diante de dois problemas. O primeiro é de eqüidade pois as condições solicitadas pelo governo federal são atendíveis apenas por municípios médios e grandes das regiões sul e sudeste, o que significará empurrar as regiões mais necessitadas do investimento para o final da fila. O segundo diz respeito a uma distorção nas competências constitucionais, pois o ensino médio na modalidade profissionalizante não é competência municipal e sim estadual. O governo não propõe parceria ou contrapartida com os estados e sim com os municípios, os quais ainda não conseguiram dar conta de suas responsabilidades especialmente na oferta de educação infantil e terão que desviar recursos para garantir contrapartidas para implantar ensino médio profissionalizante inclusive fornecimento de funcionários para manutenção, limpeza e vigilância dos futuros CEFETs.

Em trabalho recente acerca do FUNDEB já identifiquei que o papel constituciona da União não sofreu alteração. O novo fundo manteve a União "com um pape suplementar, emergencial, ajudando aqueles fundos estaduais que não alcançarem determinado patamar mínimo de valor por aluno" (ARAUJO, 2007, $p$. 151). O PDE mantém a mesma resistência governamental de enfrentar 0 debate. Não resolve a contradição de propor uma "revolução educacional" sem participação mais substancial do principal ente federado em termos de arrecadação.

\section{O FIO DA DESVALORIZAÇÃO}

Um dos pilares do PDE é o envio pelo governo federal do Projeto de Lei 619 de 2007, que estabelece um piso para os profissionais do magistério de 850 reais para 40 horas semanais a ser implantado pelos estados e municípios de forma gradativa no decorrer dos próximos três anos.

A Emenda Constitucional 53 introduziu na Carta Magna duas referências sobre piso salarial para aqueles que trabalham na educação básica pública. Até dezembro passado, em nossa Constituição estava inscrito no seu artigo 206 que um dos princípios educacionais do país seria a "valorização dos profissionais do ensino, garantidos, na forma da lei, planos de carreira para o magistério público, com piso salarial profissional e ingresso exclusivamente por concurso público de provas e títulos". A EC n'. 53 ampliou o conceito de "profissionais do ensino" para "profissionais da educação escolar", tornando dispositivo constitucional a necessidade de profissionalização dos servidores da educação e a obrigação de que os planos de carreira não sejam redigidos contemplando apenas os profissionais do magistério (docentes e profissionais que prestam suporte pedagógico direto a docência). Precisou a obrigatoriedade de criação de um piso salarial nacional, alargando também sua cobertura para os "profissionais da educação escolar pública". Este dispositivo, que deve ser efetivado por le federal, também estabeleceu que uma lei federal definisse quais categorias serão contempladas com o termo "profissionais da educação" e sobre a fixação de prazos para elaboração dos planos de carreira, os quais deverão ser constituídos em todos os âmbitos do Estado Brasileiro.
Porém, a mesma Emenda, ao alterar o artigo 60 ADCT e estabelecer as matérias que deveriam ser regulamentadas, incorporou no texto constitucional necessidade de um outro piso salarial nacional. O inciso III letra "e" tornou obrigatório que a lei regulamentadora estabeleça prazos para o envio e para aprovação do "piso salarial profissiona nacional para os profissionais do magistério público da educação básica".

Está claro que o texto introduziu uma contradição na Constituição Federal, pois no seu artigo 206, inciso VIII existe obrigação legal de um "piso salarial profissional nacional para os profissionais da educação escolar pública", redação mais abrangente que a constante na parte transitória da CF. Assim, temos dois pisos obrigatórios por lei um para todos os profissionais da educação escolar e outro para os profissionais do magistério. O governo optou pelo envio de uma proposta de piso salarial mais restrito.

Considero a proposta apresentada indecorosa. Mesmo em estados pobres como o Pará, o piso não terá incidência significativa. A proposta enfraquece - PDE, pois não se pode falar em investimento em qualidade sem melhor remuneração para magistério.

Em primeiro lugar, o governo perdeu uma ótima oportunidade de resgatar alguma credibilidade junto a este segmento do funcionalismo público depois de um primeiro mandato marcado pelos ataques aos direitos desses trabalhadores, que teve na reforma da previdência social o momento mais traumático. Tendo amparo legal para enviar ao Congresso uma proposta de piso salarial mais abrangente, que incorporasse todos os trabalhadores em educação, preferiu o caminho mais curto, 
limitando o piso apenas aos profissionais do magistério e tornando muito mais incerta a aprovação da alternativa mais abrangente. A pressão dos governos estaduais que terceirizaram grande parte dos serviços de apoio educacional a exemplo do governo do Estado do Pará, foi determinante para essa postura conservadora do governo Lula

Em segundo lugar, o PL 619/07 não representa uma real valorização dos profissionais do magistério. O valor de $\mathrm{R} \$ 850,00$ de remuneração para uma jornada de 40 horas semanais está bem abaixo da proposta apresentada pela Confederação Nacional dos Trabalhadores em Educação (CNTE) e consegue ser menor do que os valores praticados em estados considerados pobres como o Pará. O substitutivo aprovado pela Comissão de Educação da Câmara dos Deputados manteve a essência do projeto original, mesmo que alterando um pouco o valor.

Em terceiro lugar, o PL 619/07 não distingue valores de acordo com as habilitações existentes. Ao não fazer tal distinção o Projeto desestimula a obtenção de uma maior habilitação pelos profissionais do magistério.

\section{OS FIOS SÃO ANTIGOS}

Finalizo essas breves considerações sobre o PDE afirmando que seus principais fios condutores não são novos.

Estamos presenciando a continuidade do ideário pedagógico implementado nos anos FHC, baseado nos parâmetros e diretrizes curriculares e nos processos de avaliação que estão centrados numa concepção produtivista e empresarial das competências e da competitividade: o objetivo é formar em cada indivíduo um banco ou reserva de competências que the assegure empregabilidade.

Sousa (2003) enumera as principais características dos procedimentos adotados no período anterior ao governo Lula: a) ênfase nos produtos ou resultados; b) atribuição do mérito tendo por base um olhar individualizado sobre instituições ou alunos; c) dados de desempenho apresentados de forma a permitir classificações; d) predomínio de dados quantitativos; e) grande peso para a avaliação externa, de maneira desarticulada da auto-avaliação. Uma avaliação, pautada em tais características imprime uma lógica nos sistemas de ensino que se expressa "no estímulo à competição entre as instituições educacionais e no interior delas, refletindo-se na forma de gestão e no currículo" (SOUSA, 2003 p.187). A semelhança, infelizmente, não é mera coincidência.

O PDE mantém a lógica de que o pape da União é o de estimular a produção da qualidade e isso será feito pela comparação, classificação e pela seleção Esses elementos incorporam como inerente aos seus resultados a exclusão o que é incompatível com o direito de todos à educação. Premiar as escolas que atingirem determinadas metas via aumento de recursos do PDDE é bem sintomático da permanência da visão enunciada acima.

Por outro lado, mantém também a lógica da descentralização, que continua sendo vista como um instrumento de modernização gerencial da gestão pública e como um poderoso mecanismo para corrigir as desigualdades educacionais, por meio da otimização dos gastos públicos. A crítica a descentralização que foi feita a FHC deve ser reafirmada no atual momento, pois
(...) apesar de os postulados democráticos serem recorrentemente reafirmados, estes se apresentam com justicatia da como justificativa da transferência de competências daesfera central de poder paraas locais, respaldadas em orientações neoliberais, com 0 objetivo de redução do Estado às suas funções mínimas, de acordo com as inspirações/adaptações de corte hayek-smithiano. (AZEVED0, 2002, p.54).

Ao relembrarem 10 anos da morte de Paulo Freire, os educadores brasileiros

Referências bibliográficas

ARAUJO, L. Financiamento da Educação Básica no Governo Lula: elementos de ruptura e de continuidade com as políticas do governo FHC. 2005. Dissertação (Mestrado em Educação). Faculdade de Educação. Universidade de Brasília, Brasília. 182 p. AZEVEDO, J. Implicações da nova lógica de ação do estado para a educação infantil. Educação e Sociedade, São Paulo, v. 23, n. 80, p. 49-71, set. 2002.

SOUSA, Sandra M. Possíveis impactos das políticas de avaliação no currículo escolar. Cadernos de Pesquisa, 2003, $n^{\circ} .119$, p.175-190.

Recebido em agosto de 2007

Aprovado em setembro de 2007 continuarão cobrando do governo Lula a apresentação de uma proposta educacional que represente a recuperação das bandeiras democráticas e inclusivas erguidas por uma geração de lutadores pressupostos neoliberais que foram

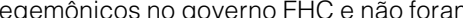
devidamente criticados e superados pelo atual governo. 